\title{
tramtrack is a transcriptional repressor required for cell fate determination in the Drosophila eye
}

\author{
Wen-Cheng Xiong ${ }^{2}$ and Craig Montell ${ }^{1,2}$ \\ Departments of ${ }^{1}$ Biological Chemistry and ${ }^{2}$ Neuroscience, The Johns Hopkins Univeristy School of Medicine, \\ Baltimore, Maryland 21205 USA
}

\begin{abstract}
Cell fate determination in the Drosophila eye is mediated by inductive events between neighboring cells in the eye imaginal disc. These inductive signals lead to differential gene expression necessary for the elaboration of different cell types in the compound eye. Several putative transcription factors have been identified previously that may be required for expression of genes that specify cell fate in the compound eye. Repression of inappropriate gene expression may be as important as transcriptional activation in the determination of cell fate. We report the identification of a mutation in the Drosophila tramtrack (ttk) locus that is required for cell fate determination in the compound eye. $t$ tk is expressed as two proteins, p69 and p88, shown previously to bind to the regulatory regions of several segmentation genes. In $t t k^{1}$, an allele missing the mRNA encoding p88, many ommatidia contained supernumerary R7 cells and decreased numbers of R1-R6 cells. $t$ t ${ }^{1 e 11}$, which appears to disrupt both Ttk proteins, was characterized by early embryonic arrest as well as transformation of ommatidial cells into nonommatidial cell types in mosaic flies. Consistent with previous proposals that the $T$ tk proteins are transcriptional repressors of segmentation genes, we detected ectopic or increased expression of the segment polarity gene engrailed in several $t t k^{1}$ larval tissues. We propose that p69 is required to repress expression of genes that are incompatible with development of photoreceptor cell fates, whereas $\mathrm{p} 88$ appears to be required to repress genes that promote the $R 7$ cell fate.
\end{abstract}

[Key Words: Drosophila; development; eye; transcription; repressor; engrailed]

Received December 15, 1992; revised version accepted March 23, 1993.

Cell fate specification in the Drosophila compound eye appears to be mediated by signals from neighboring cells within each developing cluster of cells in the eye-imaginal disc (for review, see Greenwald and Rubin 1992). A rapidly growing number of genes required in photoreceptor cell determination, particularly that of the R7 cell, have been identified. These include sevenless (sev), which encodes a receptor tyrosine kinase required in the R7 cell, and boss, the ligand for the Sev protein that is required specifically in the R8 cell (Hafen et al. 1987; Reinke and Zipursky 1988; Simon et al. 1989; Kramer et al. 1991). The recent isolation of mutations in Ras1, and the positive and negative regulators of Ras1, Sos, and Gap1, have demonstrated that $\mathrm{R} 7$ cell determination involves activation of Rasl (Rogge et al. 1991, 1992; Simon et al. 1991; Bonfini et al. 1992; Buckles et al. 1992; Gaul et al. 1992). Although the direct effector for Ras1 has not been identified, the Drosophila homolog of the mammalian serine/threonine kinase Rafl has been shown to act downstream of Rasl (Dickson et al. 1992). Considerably less is known about the events that lead to the specification of the other photoreceptor cell fates in the compound eye, although Notch, scabrous, Ellipse, and argos (also referred to as giant lens and strawberry) are exam- ples of other genes that may act in intercellular signaling events in the compound eye (Baker and Rubin 1989; Cagan and Ready 1989; Baker et al. 1990; Mlodzik et al. 1990; Freeman et al. 1992; Kretzschmar et al. 1992; Okano et al. 1992).

Many of the genes important in photoreceptor cell determination are expressed in subsets of cells and for restricted periods during their development. However, the mechanisms regulating the temporal and spatial expression of the genes important in eye development are not understood. Several transcription factors have been identified that are required in the developing compound eye-rough, glass, seven-up, sina, and yan (for review, see Moses 1991; Lai and Rubin 1992). The seven-up gene is a member of the steroid hormone receptor superfamily, although the ligand for this putative transcription factor is unknown (Mlodzik et al. 1990). Mutations in seven-up result in the transformation of four outer photoreceptor cells toward an R7 cell fate. The sina locus is essential for R7 cell development and encodes a putative transcription factor with a potential metal-binding domain (Carthew and Rubin 1990). The rough gene encodes a protein with a homeo domain required for the development of photoreceptor cells R3 and R4 (Tomlinson et 
al. 1988). Mutations in glass specifically remove photoreceptor cells, leaving the other cells in the ommatidia intact. The glass gene encodes a protein with five zinc fingers of the Cys-His class and has been shown to be a DNA-binding protein (Moses et al. 1989; Moses and Rubin 1991). Recently, a putative negative regulator of photoreceptor cell development, referred to as yan, has been identified (Lai and Rubin 1992). Loss-of-function mutations in yan result in the appearance of supernumerary R7 cells.

To identify additional genes important for the development or physiology of the compound eye, we screened P-element insertion lines for eye defects. In this paper we describe the identification of a mutation in the tramtrack $(t t k)$ gene, a proposed negative regulator of transcription. The $69-\mathrm{kD}$ Tramtrack protein (Ttk) was purified previously from embryo extracts on the basis of binding the regulatory regions of two pair-rule genes, fushi tarazu (ftz) and even-skipped (eve). The ttk gene was subsequently cloned and shown to encode two proteins, 69 and $88 \mathrm{kD}$ (p69 and p88), with different pairs of zinc fingers (Harrison and Travers 1990; Brown et al. 1991a; Read and Manley 1992). It has been proposed that p69 may play a role in the repression of zygotic gene expression of $f t z$ as well as other genes during the early nuclear division cycles prior to the cellular blastoderm stage (Brown et al. 1991a). This suggestion is supported by recent experiments indicating that $\mathrm{p} 69$ can act to repress expression of several pair-rule genes in embryos, including $f t z$ and eve. Misexpression of high levels of $p 69$ in transgenic embryos, under the control of a heat shock promoter, significantly reduces the striped pattern of expression typical of $f t z$ and eve (Read et al. 1992; Brown and Wu 1993). p88 has been shown to bind to a regulatory region of the segment polarity gene engrailed (en); however, ectopic expression of p88 does not appear to have any effect in embryos (Read and Manley 1992). These experiments raise the intriguing question as to whether either p69 or p88 is normally a transcriptional repressor of segmentation genes when expressed in the normal distribution of cells at wild-type levels.

In this study we report that in the P-element insertion allele $t t k^{1}$, there was a defect in cell fate determination in the eye resulting in the generation of an increase in the average number of $R 7$ cells and a decrease in the average number of outer photoreceptor cells per ommatidium. The mRNA encoding p88 was missing in $t t k^{1}$, indicating that the phenotype was attributable to the absence of $\mathrm{p} 88$. The role of $\mathrm{p} 88$ may be to repress inappropriate expression of genes which, if expressed, would result in disruption of the normal pattern of eye development. Consistent with the proposal that p88 is a transcriptional repressor, we detected increased levels of en expression in several $t t k^{1}$ larval tissues; the most dramatic effect was detected in the salivary glands and fat bodies, and a smaller effect was observed in eye-imaginal discs. Null $t t k$ alleles displayed early embryonic lethality and, in mosaic patches in the adult eye, transformation of ommatidial cell types into nonommatidial tissue. Thus, p69 appeared to be important for embryonic development, and both $\mathrm{p} 69$ and $\mathrm{p} 88$ were required in the eye.

\section{Results}

Identification of a mutation in the ttk locus

We identified a P-element-induced mutation in the $t t k$ locus, $t t k^{1}$, in a screen for recessive autosomal mutations affecting the development of the adult compound eye. A collection of homozygous viable P-element insertion lines (Karpen and Spradling 1992) were screened by examining the deep pseudopupil for mutations that caused defects in the arrangement or number of photoreceptor cells. The deep pseudopupil is an optical image superimposed on the surface of the eye appearing as seven large circles (Franceshini and Kirschfeld 1971). Mutations that disrupt the number or arrangement of photoreceptor cells similarly perturb the deep pseudopupil.

Evidence that the mutation identified was in $t t k$ was based on several criteria. First, on the basis of in situ hybridization to polytene chromosomes and Southern blot analyses, the mutant flies contained a single P-element insertion in the same third chromosome position, $100 \mathrm{D}$, as the $t t k$ gene (data not shown). Second, the $\mathbf{P}$ element interrupted the $t t k$-transcribed region. The $t t k$ locus is expressed as two major mRNAs, 4.2 and $5.0 \mathrm{~kb}$, encoding proteins of 643 and 813 amino acids with predicted molecular masses of 69 and $88 \mathrm{kD}$ (referred to as p69 and p88). p69 and p88 are identical through their first 286 amino-terminal residues but contain unique carboxy-terminal ends with completely different pairs of zinc fingers (Fig. 1B). On the basis of Southern blot analyses, we found that the $P$ element inserted into an intron of a 4.2-kb mRNA and an exon of a 5.0-kb mRNA (Fig. 1A).

Evidence that the mRNAs interrupted by the P element encoded the Ttk proteins was obtained by isolating cDNAs of 3.7 and $4.5 \mathrm{~kb}$, corresponding to the $4.2-$ and 5.0-kb mRNAs from a third-instar larvae eye disc library and comparing the sequences to the deduced amino acid sequences of the previously reported $t t k$ cDNAs (Harrison and Travers 1990; Brown et al. 1991a; Read and Manley 1992). The only major deviations between the $t t k$ sequences obtained in the current report and the previously reported cDNA sequences were in the $5^{\prime}$ - and $3^{\prime}$ untranslated regions. The first 192 nucleotides in the $5^{\prime}$-untranslated region were unrelated to the sequence at the $5^{\prime}$ end of the previously reported cDNAs. In addition, the length of the $3^{\prime}$-untranslated region in the $4.5-\mathrm{kb}$ eye disc cDNA was considerably longer than the 3 '-untranslated region of the previously isolated cDNA encoding p69 (Fig. 1B). Two amino acid differences between the current and previously analyzed $\mathrm{p} 88$ sequences, probably owing to sequence polymorphisms, occurred in the unique carboxy-terminal region (see Fig. 1B). The heterogeneity in the $5^{\prime}$ - and $3^{\prime}$-untranslated sequences could reflect differences in maternal and zygotic mRNAs because the previous cDNAs were isolated from libraries 


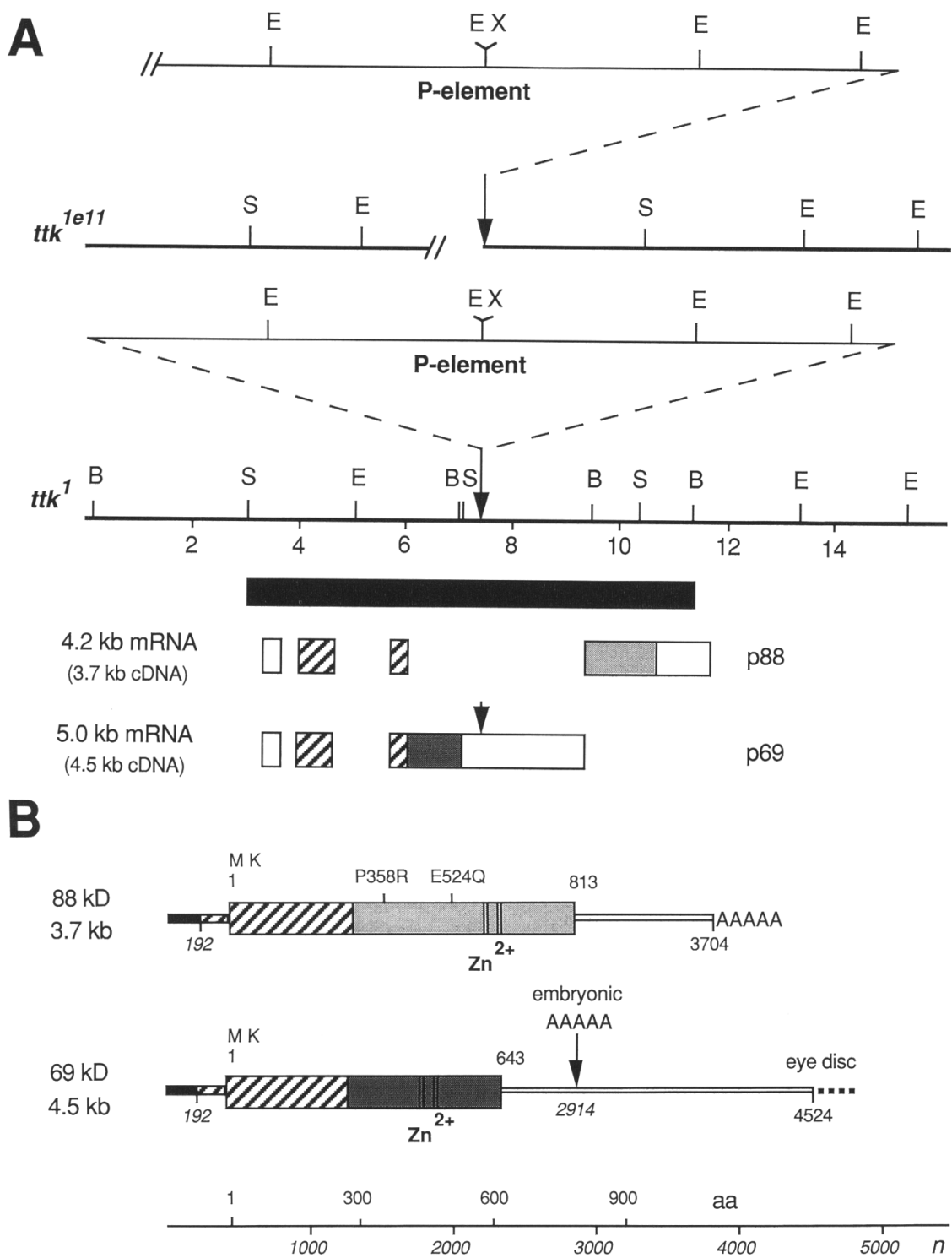

Figure 1. Physical map of $t t k \mathrm{cDNAs}$ and genomic region in wild-type, $t t k^{1}$, and $t t k^{1 e 11}$. (A) Structure of $t t k$ genomic DNA in wild-type, $t t k^{1}$, and $t t k^{1 e 11}$. A 16.0-kb portion of the $t t k^{1}$ genomic region, inserted in $\lambda t t k-1$, is represented by the horizontal line demarcated in kilobase pairs and by the restriction sites BamHI (B), $\operatorname{EcoRI}(\mathrm{E})$, and SaII (S). The insertion site of the mutator P-element is indicated by the vertical arrow above coordinate 7.5 . This insertion site corresponds to nucleotide 2741 in the $4.5-\mathrm{kb}$ cDNA, $3^{\prime}$ to the coding region, that ends at nucleotide 2285 . The P-element inserted such that its $3^{\prime}$ end is proximal to the $5^{\prime}$ end (coordinate 0 ) of the genomic region. The physical map of $t t k^{1 e 11}$ is shown above the map of $t t k^{1}$. Approximately $1.7 \mathrm{~kb}$ was deleted from the $3^{\prime}$ end of the P-element and $0.8 \mathrm{~kb}$ from the flanking genomic DNA. The approximate region transcribed in the vicinity of the P-element insertion site, determined by probing Southern blots with ${ }^{32} \mathrm{P}$-labeled cDNA prepared from adult head RNA, is indicated by the solid bar below the $t t k^{1}$ physical map. The approximate genomic regions encoding the $3.7-$ and $4.5-\mathrm{kb}$ cDNAs, corresponding to the 4.2- and 5.0$\mathrm{kb}$ mRNAs, are indicated. The hatched area represent the region encoding the amino-terminal 286 amino acids common to both cDNAs. The regions encoding the 355 and 525 amino acids unique to the $3.7-$ and $4.5-\mathrm{kb}$ cDNAs are indicated by the light and dark stippled boxes, respectively. The 5'- and $3^{\prime}$-untranslated regions are represented by the open bars. (B) Structures of the $t t k$ cDNAs. The two top horizontal lines represent the 3.7- and 4.5-kb cDNAs encoding p88 and p69, respectively. The thick portions of the lines represent the coding regions. The bottom line demarcates the amino acid and nucleotide positions encoded in the cDNAs. The amino acids are represented by the numbers above the lines and the nucleotides by the numbers below the lines. The common 5 '-untranslated region and amino-terminal 288 amino acids encoded by the $3.7-$ and $4.5-\mathrm{kb}$ cDNAs are indicated by hatching. The coding regions unique to the $3.7-$ and $4.5-\mathrm{kb}$ cDNA are represented by the light and dark stippled regions, respectively. The positions of the distinct pairs of zinc fingers in p88 and p69 are shown. Several differences are shown between the 3.7- and 4.5-kb cDNAs isolated from the eye disc library and the cDNAs isolated previously from embryonic libraries. The 192-nucleotide region at the $5^{\prime}$ end of the untranslated region, indicated by the thick black line, was completely divergent. The length of the 3'-untranslated region in the cDNAs encoding p69 also diverged significantly. The positions of the $3^{\prime}$ ends of the cDNAs isolated from the eye disc and embryonic libraries are shown. $\mathrm{M}$ and $\mathrm{K}$ above the 3.7- and 4.5-kb cDNAs represent the two additional amino acids, methionine and lysine, at the amino teminus of the eye disc cDNAs. Also noted is the arginine $(R)$, instead of proline $(P)$, at residue 358 and the glutamine $(\mathrm{Q})$, instead of glutamic acid $(\mathrm{E})$, at residue 524. pcttk-37, but not pcttk-45, contained a poly $(\mathrm{A})$ tail.

prepared from either early embryos or mixed staged embryos. The cDNAs isolated in the current analyses were obtained from an eye disc cDNA library. Alternatively, the unrelated $5^{\prime}$ - and $3^{\prime}$-untranslated regions could be the result of different RNA splicing patterns in embryos and larval eye-imaginal discs.

A third piece of evidence that the mutation was in $t t k$ was obtained by probing an RNA blot containing wild- type and $t$ tk RNA. Using isoform-specific probes, we found that the wild-type $4.2-\mathrm{kb}$ mRNA was missing and the $5.0-\mathrm{kb}$ mRNA was truncated to $4.2 \mathrm{~kb}$ (Fig. 2). Thus, the concentration or size of both ttk mRNAs was affected in the P-element insertion line.

Fourth, the mutant phenotype was restored to wild type in a high percentage of lines in which the $P$ element was mobilized from the third chromosomal position at 


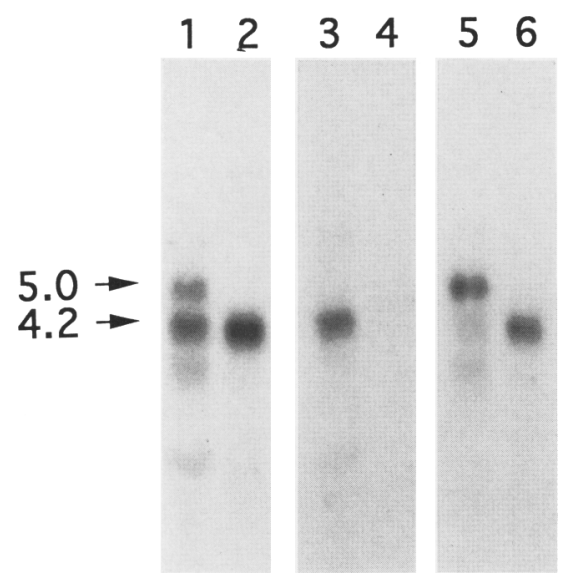

Figure 2. Northern blot analyses of $t t k$ RNA expressed in $t t k^{1}$. RNAs prepared from wild-type (lanes 1,3,5) and $t k^{1}$ (lanes 2,4,6) adult flies were fractionated on a $1 \%$ agarose, $6 \%$ formaldehyde gel, transferred to a nylon membrane, and probed with either the entire $3.7-\mathrm{kb}$ cDNA (lanes 1,2$)$ or the unique regions of the 3.7-kb (lanes 3,4) and 4.5-kb cDNAs (lanes 5,6). The 3.7- and $4.5-\mathrm{kb}$ cDNAs contain the entire coding regions of the $4.2-$ and $5.0-\mathrm{kb}$ mRNAs, respectively. The probe specific to the $3.7-\mathrm{kb}$ cDNA was a $0.8-\mathrm{kb}$ SacI-EcoRI fragment from the extreme $3^{\prime}$ end of the cDNA. The probe specific to the $4.5-\mathrm{kb}$ cDNA was a cDNA that was a truncated version of the $4.5-\mathrm{kb}$ cDNA extending $2.6 \mathrm{~kb}$ from the $3^{\prime}$ end of the $4.5-\mathrm{kb}$ cDNA. The $5.0-$ and 4.2-kb mRNAs are indicated.

100D (see Materials and methods). Of 19 excision lines, 14 reverted to wild type, demonstrating that the $t t k^{1}$ phenotype was induced by the P-element rather than by a spontaneous mutation. One excision line exhibited a phenotype similar to $t k^{1}$, and the remaining four lines were homozygous lethal. One of the lethal excision alleles, $t t k^{1 e 11}$, appeared to be a null allele (see below).

Northern, Southern, and DNA sequencing analyses suggested that $p 88$ was eliminated in $\mathrm{ttk}^{1}$ and both p69 and $p 88$ were affected in $\mathrm{ttk}^{1 e 11}$

The site of the P-element insertion in $t k^{1}$ was determined by DNA sequence analysis (see Materials and methods). We found that the P element inserted $0.45 \mathrm{~kb}$ from the $3^{\prime}$ end of the coding region of the $4.5-\mathrm{kb}$ cDNA. Therefore, the truncated $5.0-\mathrm{kb}$ mRNA expressed in $t \mathrm{k}^{1}$ could still potentially encode $\mathrm{p} 69$. Because the truncated 5.0-kb mRNA in $t t k^{1}$ was expressed at a level similar to that of the full length $5.0-\mathrm{kb}$ mRNA in wild type (Fig. 2), it is likely that expression of p69 was unaffected in $t t k^{1}$. The $\mathrm{p} 88$ protein was eliminated or dramatically reduced in $t k^{1}$ because the 4.2-kb mRNA was not detected in RNA blots (Fig. 2). Insertion of the P element in the intron of the $4.2-\mathrm{kb}$ mRNA may have interfered with the processing of this mRNA.

To determine whether $t t k^{1 e 11}$ was associated with a deletion, Southern blots containing $t t^{1 e 11} \mathrm{fly}$ genomic DNA were probed with a series of small DNA probes from the $4.5-\mathrm{kb}$ cDNA (data not shown). We found that $\sim 1.7 \mathrm{~kb}$ was deleted from the $3^{\prime}$ end of the $P$ element and $0.8 \mathrm{~kb}$ of flanking genomic DNA (Fig. 1). The $0.8-\mathrm{kb}$ deletion removed the region encoding the zinc fingers in p69. Even if the truncated p69 protein was stably expressed, it was likely to be devoid of any DNA-binding capacity. Therefore, $t t k^{1 e 11}$ affected both Ttk proteins.

\section{Expression of ttk RNA during development}

Expression of $t$ tk RNA during Drosophila development was investigated by probing an RNA blot, containing RNA prepared from various stages throughout development, with $t$ tk DNA (Fig. 3). The DNA probe was to the region common between the $4.2-$ and $5.0-\mathrm{kb}$ mRNAs to enable the relative concentrations of the two predominant mRNA forms to be assessed. The results of the analyses demonstrated that $t t k$ was expressed at the highest levels in embyros and in the adult. Longer exposures of the autoradiograph demonstrated that $t t k$ is expressed at lower levels throughout development. The 5.0-kb mRNA was expressed at levels slightly higher than those of the 4.2-kb mRNA during development, whereas both $t t k$ mRNAs were expressed in approximately equal proportion in the adult. In addition to the 5.0- and 4.2-kb mRNAs, a slightly less abundant mRNA, $\sim 3.6 \mathrm{~kb}$, was observed specifically in the adult (Figs. 2 and 3); however, the structure of this mRNA has not

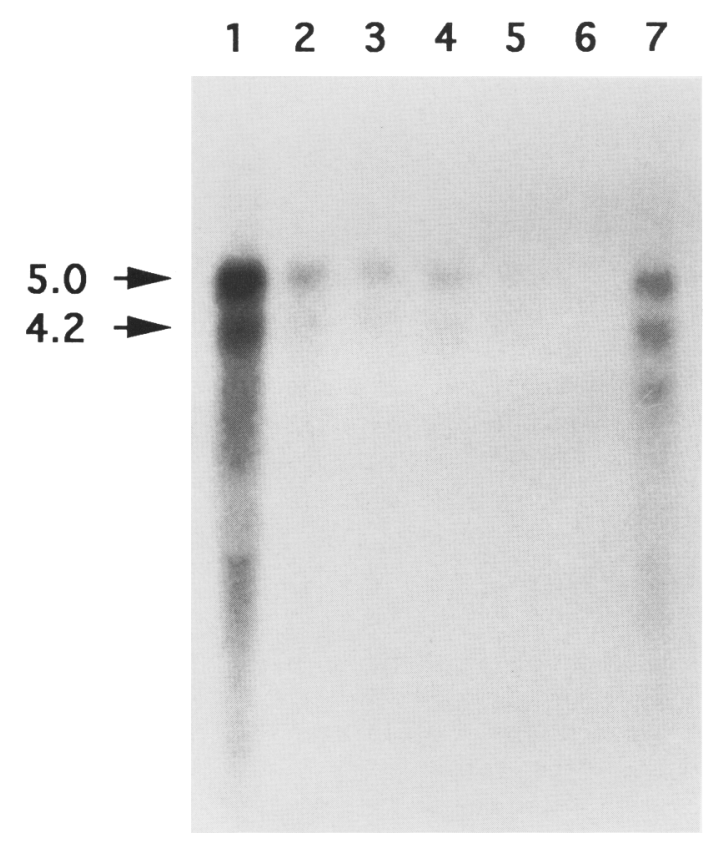

Figure 3. Expression of $t t k$ mRNA during development. Total RNA was prepared from a wild-type Canton-S strain at various times during development and fractionated on a $6 \%$ formaldehyde, $1.0 \%$ agarose gel, transferred to GeneScreen Plus, and probed with a $1.0-\mathrm{kb}$ EcoRI-SacI fragment from the extreme 5' end common to both $t$ tk mRNAs. (Lane 1) Embryos; (lane 2) first-instar larvae; (lane 3) second-instar larvae; (lane 4) thirdinstar larvae; (lane 5) early pupae; (lane 6) late pupae; (lane 7) adults. 
been determined. The relatively faint band, $\sim 2.1 \mathrm{~kb}$ (shown in Fig. 2, lane 1), was not observed consistently and might be a degradation product.

\section{Fewer outer photoreceptor cells and extra $R 7$ cells in many $\mathrm{ttk}^{1}$ ommatidia}

A wild-type compound eye contains $\sim 800$ facets or ommatidia, each of which contains eight photoreceptor (R) cells. Six of the photoreceptor cells, R1-R6, extend the full depth of the ommatidia and contain large rhabdomeres positioned along the periphery of the ommatidia. The rhabdomeres of the R7 and R8 cells are smaller and occupy the central upper (distal) and lower (proximal) portions of the ommatidia, respectively. Consequently, only seven of the eight photoreceptor cells are present in any given cross section.

The $t t k^{1}$ retina was found to contain $>50 \%$ aberrant ommatidia with abnormal numbers and positioning of photoreceptor cells. Shown in Figure 4 are cross sections of the distal region (R7 level) of the compound eye. In contrast to wild-type ommatidia, which always contain seven $R$ cells (Fig. 4A), ttk ommatidia were characterized by a variable number of photoreceptor cells (Fig. 4B). Table 1 lists the number of outer (R1-R6) photoreceptor cells and $R 7$ cells in each ommatidium. The identities of the photoreceptor cells, as outer or R7 cells, were based on the position and size of the rhabdomeres and on genetic criteria (see below). Among ommatidia with altered numbers of R1-R6 cells, $98 \%$ displayed a decreased number of outer photoreceptor cells. However, among ommatidia with aberrant numbers of R7 cells, $87 \%$ had extra R7 cells. Typical ommatidia with decreased numbers of outer photoreceptor cells and additional R7 cells are shown (Fig. 4C,D). The average numbers of R1-R6 and R7 cells were 5.4 and 1.4 per ommatidium, respectively; however, the exact number of cells was difficult to score as some rhabdomeres were fused or split. If only abnormal ommatidia were considered, the average number of outer R cells dropped further to 4.9 and R7 cells increased to 1.8 . The extra $R 7$ cells did not appear to result from the simple transformation of R1-R6 cells into $\mathrm{R} 7$ cells, as there were many $t t k^{1}$ ommatidia with extra R7 cells in addition to the normal complement of six outer photoreceptor cells (Table 1). Other $t t k^{1}$ ommatidia contained one R7 cell but fewer than six outer photoreceptor cells (Table 1). Examination of the proximal cross section (R8 level) demonstrated that all of the ommatidia in $t t k^{1}$ contained one small rhabdomere, indicating that there was no defect in the number of $\mathrm{R} 8$ cells (data not shown). In addition to the defects in the eyes, the fertility of $t \mathrm{k}^{1}$ flies was reduced significantly, indicating that $t t k^{1}$ may also have a role in oogenesis.

To obtain additional evidence that the extra cells with small rhabdomeres are R7 cells, a double mutation was constructed between $t t k^{1}$ and a null allele of the ninaE locus, nina $E^{I 17}$, which disrupts the opsin gene expressed in the R1-R6 cells. The ninaE $E^{I 17}$ mutation results in degeneration of the outer photoreceptor cells prior to
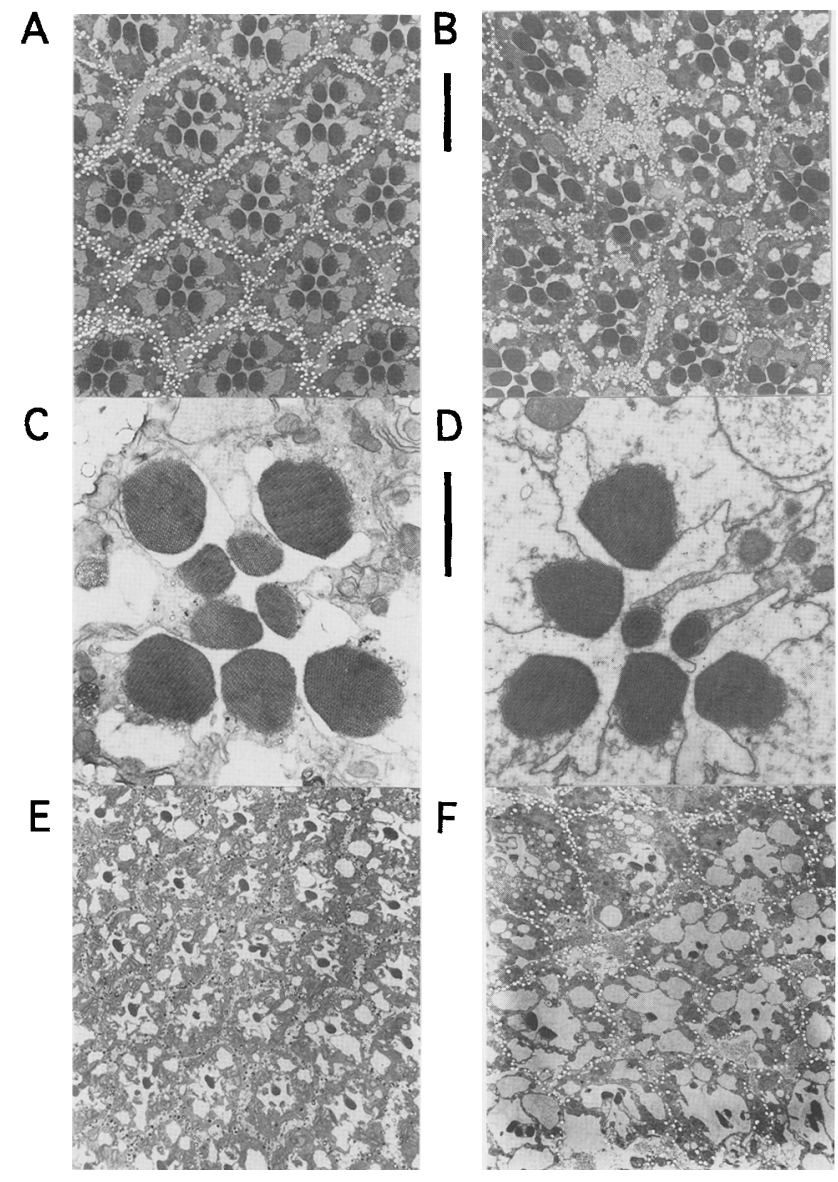

Figure 4. Many $t t k^{1}$ ommatidia contain supernumerary photoreceptor cells with small rhabdomeres and fewer outer photoreceptor cells. Thin sections from the distal region of the adult compound eye ( $30 \mu \mathrm{M}$ depth) examined by transmision electron microscopy. $(A)$ Wild-type Canton-S strain; $(B-D) t t k^{1}$; (E) nina $E^{117} ;(F)$ nina $E^{117}, t t k^{1}$. The scale bar between $A$ and $B$ represents $16 \mu \mathrm{M}$ in $A, B, E$, and $F$; that between $C$ and $D$ is equivalent to $2 \mu \mathrm{M}$ in $C$ and $D$.

eclosion; therefore, only a single central small rhabdomere corresponding to the R7 cell appears in distal cross sections (Fig. 4E; O'Tousa et al. 1989). Occasionally, the central R7 rhabdomere in ninaE $E^{I 17}$ was split; however, no ommatidium contains more than one small rhabdomere (Fig. 4E). In contrast to nina $E^{I 17}$, many $t t k^{1}$, nin $E^{I 17}$ double mutant ommatidia contain more than one rhabdomere, demonstrating that the extra $\mathrm{R}$ cells were refractory to the R1-R6 specific degeneration caused by the nina $E^{I 17}$ mutation (Fig. 4F). Hence, it appears that the additional small rhabdomere-containing cells were $\mathrm{R} 7$ cells.

Examination of developing eye-imaginal disc with a neuronal-specific antibody indicated that the stereotypic pattern of R-cell development was disrupted in $t t k^{1}$ (data not shown). Differentiation of the photoreceptor cells begins in the third-instar larval eye-imaginal disc in a groove referred to as the morphogenetic furrow. Anterior to the furrow, cells are undifferentiated, and posterior to 
Table 1. Number of R1-R6 and R7 cells in $\mathrm{ttk}^{1}$ ommatidia

\begin{tabular}{lcccccr}
\hline \multicolumn{7}{c}{ Number of cells } \\
\cline { 3 - 7 } R1-R6 & Ommatidia & 0 & 1 & 2 & 3 & 4 \\
\hline 1 & 2 & & & 1 & & 1 \\
2 & 1 & 1 & & & & \\
3 & 1 & & & 1 & & \\
4 & 15 & 2 & 6 & 5 & 2 & \\
5 & 38 & 3 & 14 & 12 & 8 & 1 \\
6 & 97 & 2 & 73 & 20 & 2 & \\
7 & 1 & & & & 1 & \\
\hline
\end{tabular}

the furrow the photoreceptor cells develop in a sequential pattern. Differentiation begins with R8, followed by $\mathrm{R} 2$ and R5, R3 and R4, R1 and R6 and, finally, R7 (Tomlinson and Ready 1987). Photoreceptor cell differentiation can be detected by staining eye-imaginal discs with a neuronal-specific antibody, such as BP104 (Bieber et al. 1989). In wild-type eye discs, the development and staining patterns of the $\mathrm{R}$ cells are the same among the clusters within each column. However, in $t t k^{1}$ eye discs, the pattern of staining among clusters within a column was variable; the staining in some clusters appeared indistinguishable from wild-type, and in others the numbers or relative orientation of the cells staining with $\mathrm{BP} 104$ varied. The variable staining pattern was consistent with the observation that some ommatidia in $t t k^{1}$ adults contained a normal complement of photoreceptor cells and others contained extra R7 cells or fewer outer photoreceptor cells as described above. In addition, the intensity of staining with BP104 was reduced in $t$ th relative to wild-type eye discs.

\section{Null mutants for ttk result in embryonic lethality and, in mosaic flies, transformation of ommatidial to nonommatidial tissue}

$t t k^{1}$ did not appear to be a null allele because 4 of the 19 lines in which the $\mathrm{P}$ element was mobilized from the third chromosomal position at 100D were homozygous lethal. Evidence that the lethality associated with the lethal excision lines was not the result of insertion of the mobilized P element in other essential genes at new chromosomal positions, or to a background lethal mutation, was obtained by placing $t t k^{1}$ and the lethal excision alleles in trans with a deletion that removes the $t t k$ locus. We found that $t t k^{1}$, as well as each of the lethal excision alleles, when placed in trans with a deletion of the corresponding region, $\mathrm{Df}(3 \mathrm{R}) a w d^{K R B}$, resulted in lethality. The strongest $t t k$ excision allele, $t t^{1 e 11}$ may be a null allele, as $t k^{1 e 11}$ in trans with $\mathrm{Df}(3 \mathrm{R}) a w d^{K R B}$ was similar in phenotype to $t t k^{1 e 11}$ homozygotes. The lethality associated with $t t \mathrm{k}^{1 e 11}$ homozygotes appeared to result from an arrest in development early in embryogenesis, before dorsal closure (Fig. 5). The $t k^{1 e 11}$ embryos formed segments but displayed severe perturbations of cuticular structures. In addition, the Filzkörper and head structures, such as the mouth hooks, typically failed to form.

The effect of the strong $t t k$ allele, $t t k^{1 e 11}$, on formation of the adult eye was examined by performing somatic mosaic analysis. Homozygous $t t k^{1 e 11}$ mutant cells were genetically marked using an ectopic copy of the white $(w)$ gene (a recessive gene affecting eye color), inserted on the third chromosome at $90 \mathrm{~F}$, as a cell autonomous marker. Clones of homozygous mutant cells were made by inducing mitotic recombination with X-ray irradiation in the third larval instar. Photoreceptor cells that were $w^{-}$were homozygous mutant in an otherwise wild-type eye. Ommatidia in small mutant clones appeared to be devoid of any photoreceptor cells or cone cells (Fig. 6). Because there is no lineage restriction in the formation of an ommatidium, cells of the different genotypes mix at the borders of mutant clones. By examination of phenotypically wild-type photoreceptor cells in the border areas for the white marker, it is possible to assess which cells require the ttk gene product. We found that all photoreceptor cells were genotypically wild type, indicating that the $t t k$ gene product was required cell autonomously in each of the photoreceptor cells.

Occasionally, compound eyes with large mutant clones were obtained, resulting in a strong rough eye phenotype in the region surrounding the mosaic patch (Fig. 7). The rough areas were characterized by the presence of extra mechanosensory bristles between some
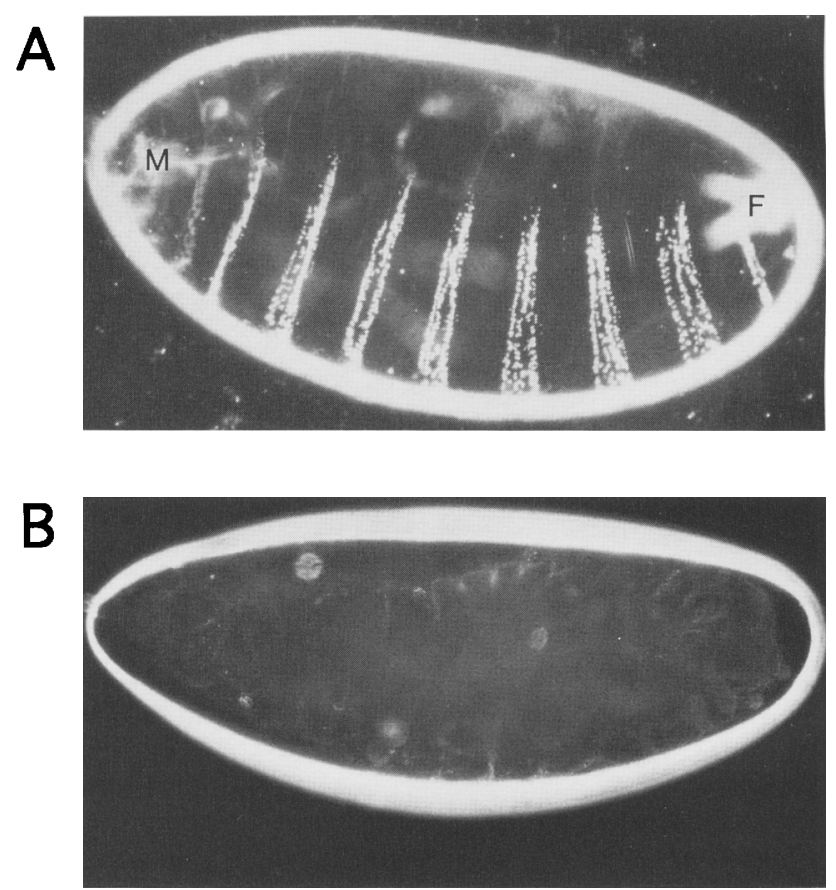

Figure 5. Cuticle preparation of wild-type and $t t k^{1 e 11}$ embryos. Embryos were mounted in Hoyer's medium, as described (Ashburner 1989|, and viewed by dark-field microscopy. (A) Wildtype; $(B) t t k^{1 e 11}$. The mouth hooks $(\mathrm{M})$ and Filzkörper $(\mathrm{F})$ are indicated in $A$. 


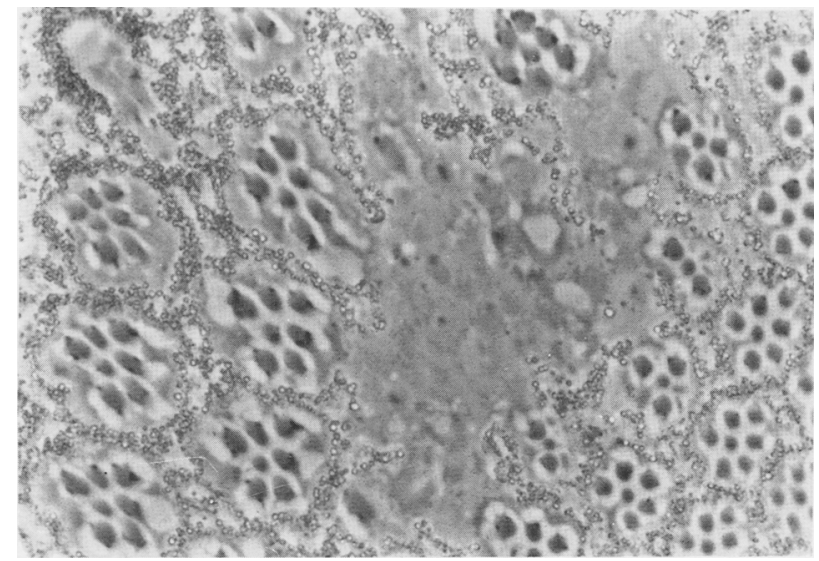

Figure 6. Phenotype of $t k^{1 e 11}$ mosaic compound eye viewed by light microscopy. Tangential cross section in the distal region (30 $\mu \mathrm{M}$ depth) of a mosaic patch.

ommatidia and the absense of mechanosensory bristles between others. The size and shape of many of the facets was also altered. No $w^{-}$areas were observed in the rough patches, apparently owing to complete loss of ommatidia in the mutant regions. Areas that would normally consist of ommatidal tissue in a wild-type eye were transformed to nonommatidial tissue with numerous hairs. These results indicated that the null mutation in $t t k$ prevented development of all normal cell types in the compound eye.

\section{Enhancement of en expression in several $\mathrm{ttk}^{1}$ larval tissues}

The 699 protein has been proposed to be a transcriptional repressor of several pair-rule genes, including $f t z$, eve, and hairy, and p 88 has been suggested to be a repressor of the segment polarity gene en (Harrison and Travers 1990; Brown et al. 1991a; Read and Manley 1992; Read et al. 1992; Brown and Wu 1993). To provide in vivo evidence that $\mathrm{p} 88$ is a repressor, we compared $f t z$, hairy, and en expression in wild-type and $t t k^{1}$ larval tissues by immunostaining. The intensity of staining with $\mathrm{ftz}$ and hairy was indistinguishable between wild-type and $t t k^{1}$. However, several tissues expressed $e n$ at a higher level in $t t k^{1}$ than in wild type. The most dramatic difference was observed in the salivary glands and fat bodies (Fig. 8A,B). A much smaller, but reproducible, enhancement of expression was also detected in $t t k^{1}$ eye-imaginal discs (Fig. 8C,D), where expression was detected in all of the photoreceptor cells, the cone cells, and undetermined cells behind the morphogenetic furrow. Although the increase in en expression in eye discs was not dramatic, in a blind experiment, 20 eye discs were all successfully identified as $t t k^{1}$ or wild type on the basis of $e n$ staining. In other larval tissues, such as the brain, central nervous system, and wing, leg, and haltere discs, the intensity of en staining was similar in $t t k^{1}$ and wild type. The en embryonic expression pattern of 14 major stripes typical of wild-type embryos was also detected in nearly all $t t k^{1}$ embyos (data not shown). However, in a few $t t k^{1}$ embyos $(<2 \%)$, the stripes were broader than usual (data not shown). Additional experiments will be required to determine whether this was the result of a background mutation or a slight effect on en expression in occasional $t t k^{1}$ embryos. To determine whether there was ectopic expression of $f t z$, eve, and $e n$ in $t t k^{1 e 11}$, embryos were collected from a $t k^{1 e 11} /+$ inter se cross and stained with antisera. No ectopic staining was detected with $f t z$, eve or en.

\section{Discussion}

In this paper we describe the identification and characterization of a mutation in $t t k$, a locus required for the development of the adult compound eye. The original $t t k$ allele, $\left(t t k^{1}\right)$, was isolated in a genetic screen, using

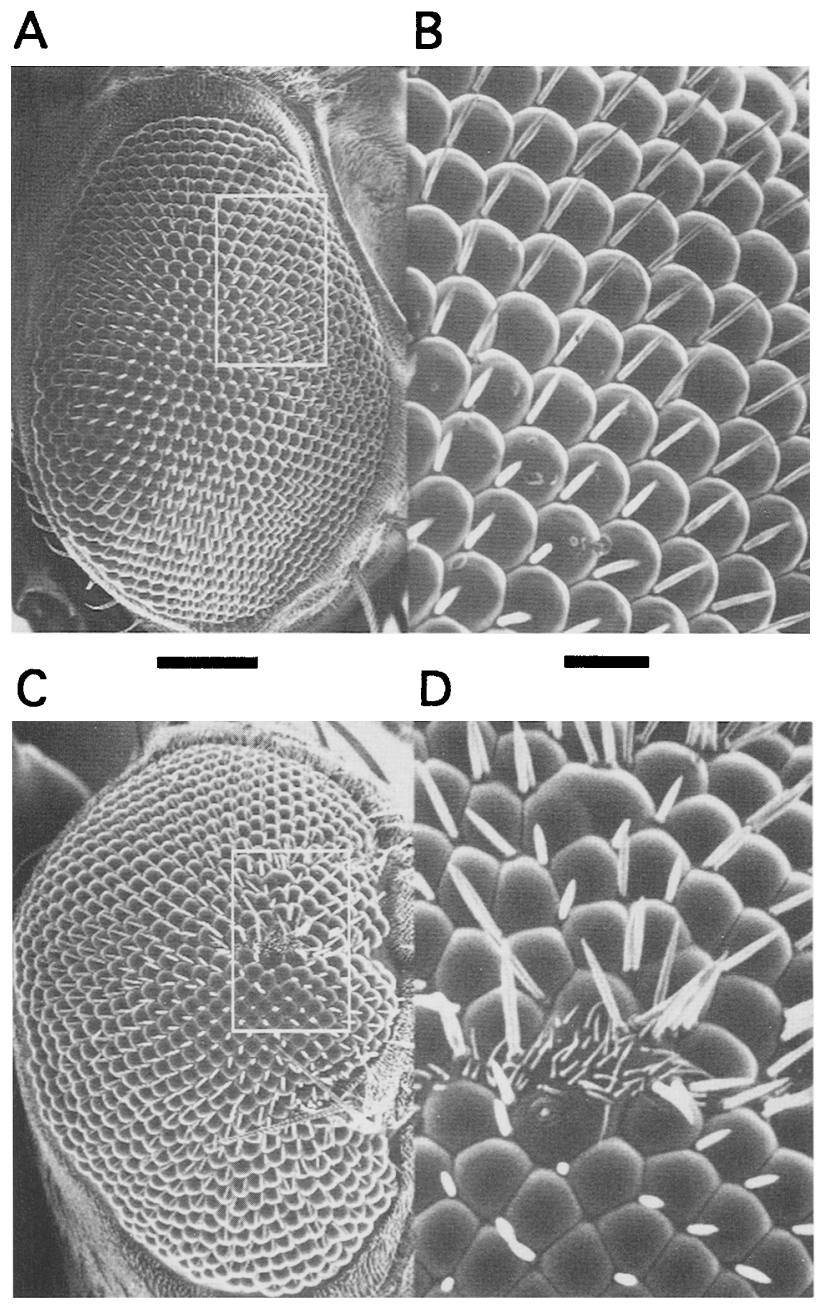

Figure 7. Mosaic $t t k^{1 e 11}$ compound eyes viewed by scanning electron microscopy. $(A, B)$ Wild-type and mosaic; $(C, D) t t k^{1 e l l}$. The rectangles in $A$ and $C$ indicate the regions examined using higher magnification in $B$ and $D$. Bars, $100 \mu \mathrm{M}(A, C)$ and $20 \mu \mathrm{M}$ $(B, D)$. 
Figure 8. Expression of en in $t t k^{1}$ larval tissues. Wild-type and $t t k^{1}$ tissues from third-instar larvae stained with an en mouse monoclonal antiserum are shown. (A) Wild-type salivary gland (S) and fat body $(\mathrm{F}) ;(B) t t k^{1}$ salivary gland $(\mathrm{S})$ and fat body $(\mathrm{F}) ;(C)$ wild-type eye $(\mathrm{E})$-antennal $(\mathrm{A})$ imaginal disc; $(D) t t k^{1}$ eye-antennal imaginal disc.
A

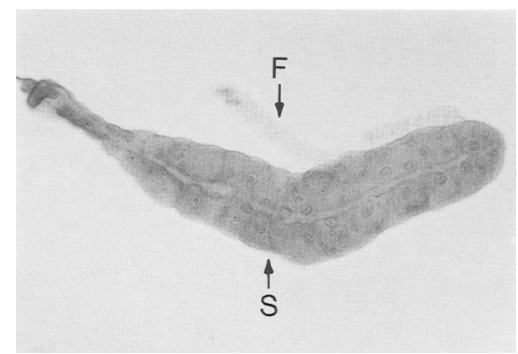

C

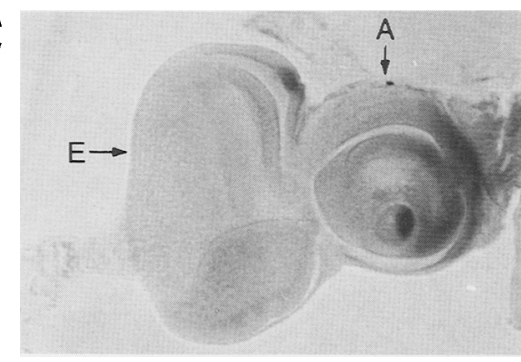

B

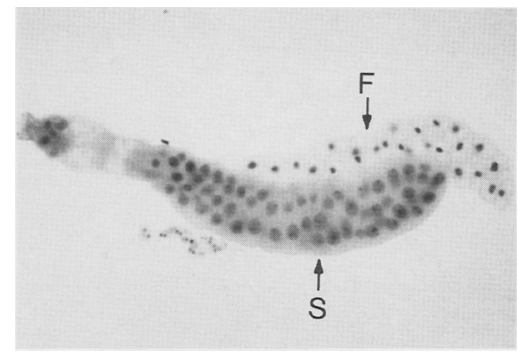

D

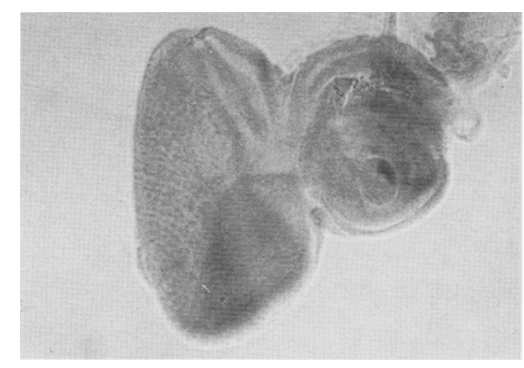

P-element insertion mutagenesis, to identify loci required for the development or physiology of the adult compound eye. The $69-\mathrm{kD} t t k$ protein was purified previously on the basis of binding the transcriptional control regions of two pair-rule genes $\mathrm{ftz}$ and eve (Harrison and Travers 1990; Brown et al. 1991a; Read and Manley 1992). The $t t k$ gene was subsequently cloned by screening expression libraries with the $t t k$ DNA-binding site and shown to encode two proteins, p69 and p88, with different pairs of zinc fingers of the Cys-His class (Harrison and Travers 1990; Brown et al. 1991a; Read and Manley 1992). We have shown that in the $t k^{1}$ allele, there is a defect in the development of the compound eye characterized by an increase in the average number of $R 7$ cells and a decrease in the average number of R1-R6 cells. In contrast to $t k^{1}$, the null allele $t t k^{1 e 11}$ was characterized by early developmental arrest and embryonic lethality. These embyros were segmented but displayed severe defects in cuticle formation. Somatic mosaic analyses demonstrated that the null mutation in ttk results in transformation of normal cell types in the compound eye with nonommatidial tissue.

\section{Possible source of the extra $R 7$ cells in $\mathrm{ttk}^{1}$}

In addition to $t t k^{1}$, several other mutations have been identified that result in supernumerary R7 cells. One example is the seven-up mutation (Mlodzik et al. 1990). Absence of seven-up function results in the transformation of R1, R3, R4, and R6 cells to an R7 cell fate. Additional photoreceptor cells with small rhabdomeres, presumably R7 cells, are observed in many ommatidia in distal eye sections from rough ${ }^{1}$ flies (Tomlinson et al. 1988). The rough and seven-up gene products may act to repress development of the $\mathrm{R} 7$ cell fate in other photoreceptor cells. Consistent with this proposal, ectopic expression of rough in the $\mathrm{R} 7$ cell precursor results in transformation of the R7 precursor into an R1-R6 type of photoreceptor cell (Basler et al. 1990; Kimmel et al. 1990). The yan locus, encoding an ETS DNA-binding domain, is another putative negative regulator of $R 7$ cell development (Lai and Rubin 1992).

Non-neuronal cone cell precursors and mystery cells can also be converted into an R7 cell fate. The extra R7 cells in yan appear to be derived from cone cell precursors or from the general pool of uncommitted cells. Expression of a constitutively active Sevenless protein appears to cause the conversion of mystery cells and cone cell precursors into R7 cells (Basler et al. 1991). Similarly, the formation of supernumerary $\mathrm{R} 7$ cells from cone cell precursors and mystery cells is induced by the expression of a dominant activating Rasl protein, loss-offunction Gapl alleles, or ectopic expression of boss (Fortini et al. 1992).

The source of the extra $\mathbf{R} 7$ cells in the $t t k^{1}$ allele may be the cone cell precursors and/or mystery cells because nearly $60 \%$ of ommatidia with supernumerary R7 cells contained too many outer photoreceptor cells to account for the additional R7 cells. Most notably, $>40 \%$ of the ommatidia with extra R7 cells displayed the normal complement of six outer photoreceptor cells. Therefore, it is unlikely that these extra R7 cells developed from R1-R6 cell precursors. However, it cannot be excluded that some of the additional R7 cells in $t k^{1}$ developed from R1-R6 cell precursors.

\section{p69 and p88 appear to have different roles}

The $t t k$ gene is expressed as two alternatively spliced mRNAs encoding two proteins, $\mathrm{p} 69$ and $\mathrm{p} 88$, which share common amino termini but differ from each other over the carboxy-terminal $55 \%$ and $65 \%$ of the proteins, respectively. Both $\mathrm{p} 69$ and $\mathrm{p} 88$ contain different pairs of zinc fingers, suggesting that each Ttk protein may regulate different target genes. Consistent with this proposal, p69 and p88 have been shown recently to have distinct 
DNA-binding specificities in vitro (Read and Manley 1992). The $\mathrm{p} 69$ protein has been shown to bind in vitro to multiple sites within important regulatory elements of the pair-rule genes $f t z$ and $e v e$, and p88 binds the regulatory element of the segment polarity gene en (Harrison and Travers 1990; Brown et al. 1991a; Read and Manley 1992). The differences in DNA-binding specificities of p69 and p88 in vitro raises the issue as to whether the proteins have different roles in vivo.

The analyses described in this report indicate that $\mathrm{p} 69$ and $\mathrm{p} 88$ have different roles. The $t t k^{1}$ mutant, in which the mRNA encoding $\mathrm{p} 88$ was not detected, was characterized by extra R7 cells and a decreased number of outer photoreceptor cells. In contrast to $t t k^{1}$, the $t t k^{1 e 11}$ excision allele, which affects both p69 and p88, displayed early embryonic lethality and, in mosaic flies, transformation of all ommatidial cells into nonommatidial tissue containing numerous hairs. This phenotypic analysis indicates that p69 is most important during embryogenesis and both p69 and p88 are required in the compound eye. The different roles of the two Ttk proteins do not appear to be the result of different expression patterns in the eye-imaginal disc. Using isoformspecific antisera, it appears that both p69 and p88 are expressed predominantly in the subretinal cells and cone cells (W.-C. Xiong and C. Montell, unpubl.). These results are consistent with the proposal that the two different $\mathrm{Ttk}$ proteins have different target genes in vivo.

The replacement of ommatidia with nonommatidial tissue suggests that there is an alteration in cell fate determination in the $t t k^{1 e 11}$ mosaic patches. If cell death was responsible for the absence of ommatidial units, then $t k^{1 e 11}$ mosaic eyes would be expected to be characterized by decreased numbers of ommatidia without the substitution of nonommatidial tissue. We propose that the role of p69 is to repress expression of genes that are incompatible with development of all normal cell types in the compound eye.

Our results suggesting that p69 is more important than $\mathrm{p} 88$ during embyrogenesis are supported by recent experiments examining the effects of ectopic expression of high levels of p69 and p88 in an otherwise wild-type embryo (Read et al. 1992; Brown and Wu 1993). Misexpression of $\mathrm{p} 69$ results in repression of several pair-rule genes and causes embryonic lethality characterized by severe cuticular defects. Conversely, ectopic expression of $\mathrm{p} 88 \mathrm{had}$ no apparent effect on gene expression in the embryos or on cuticle formation, suggesting that $\mathrm{p} 88$ does not appear to affect segmentation gene expression in the embryo. Perhaps $\mathrm{p} 88$ functions to repress expression of segmentation genes only in concert with other factors that are not expressed in the embyro but are expressed later in development. Despite these observations, it seems likely that $\mathrm{p} 88$ has some function during embryogenesis, as the $t \mathrm{tk}^{1}$ mutaton was lethal in trans with a deficiency for the $t t k$ locus.

Although recent studies indicate that $\mathrm{p} 69$ represses expression of several pair-rule genes in embryos, the typical pair-rule phenotype, characterized by deletion of alternating segments, was not observed as a result of the disruption of both Ttk proteins in $t t k^{1 e 11}$. The gross effect on cuticle formation in $t t^{1 e 11}$ embryos and in embryos ectopically expressing p69 suggests that the Ttk proteins may have some targets in embyros that are not segmentation genes. Our results indicate that neither $f t z$, eve, nor en was misexpressed in $t t k^{1 e 11}$ embyos; however, maternal Ttk was still present in these embryos. If $\mathrm{p} 69$ has a role in repressing other genes, in addition to the segmentation genes, in early embryos, then elimination of maternal Ttk might cause general defects rather than specific segmentation defects. Further studies, including removing maternal Ttk by constructing germ-line mosaics will be required to determine which genes are important in vivo targets for Ttk in the embryo.

\section{Potential role and targets for $p 88$ in the compound eye}

The Ttk proteins have been shown to display divergent DNA-binding specificities and have been suggested to play roles as transcriptional repressors of segmentation genes such as $f t z$, eve, and en (Read and Manley 1992). Therefore, the mechanism by which $\mathrm{p} 88$ could regulate gene expression in the eye might be transcriptional repression. Consistent with the proposal that $\mathrm{p} 88$ is a transcriptional repressor, we have shown that expression of $e n$ is enhanced dramatically in the larval salivary glands and fat bodies and increased to a lower extent in eyeimaginal discs. We cannot conclude that the disruption in normal eye development in $t k^{1}$ was specifically the result of misexpression of $e n$; however, it is likely that p88 acts directly as a transcriptional repressor of $e n$ because p 88 has been shown previously to bind the promoter region of en in vitro (Read and Manley 1992).

Because $\mathrm{p} 88$ appears to be a transcriptional repressor in vivo, potential targets other than en are loci in which ectopic expression of the wild-type protein partially or fully phenocopy $t t k^{1}$. It is difficult to suggest potential targets for p 69 in the compound eye because the phenotype of $t \mathrm{k}^{1 e 11}$ was unique and was the result of disruption of both Ttk proteins. However, other mutants have been described that display phenotypes reminiscent of $t t k^{1}$. One of the roles of $\mathrm{p} 88$ could be to repress expression of genes which, if expressed, would transform non$\mathrm{R} 7$ cell precursors to $\mathrm{R} 7$ cells. On the basis of this criterion, one candidate target for $\mathrm{p} 88$, boss, encodes the ligand for Sev. Ectopic expression of boss, under control of the heat shock promoter, results in supernumerary $\mathbf{R} 7$ cells (Van Vactor et al. 1991). However, if expression of boss were completely derepressed in $t t k^{1}$, one would expect extra R7 cells in all $t t^{1}$ ommatidia. Furthermore, boss could not be the only target for p 88 , as ectopic expression of boss does not result in fewer outer photoreceptor cells in any ommatidia. Another potential target for $\mathrm{p} 88$ is one of the effectors for Ras1.

An alternative role of $\mathrm{p} 88$ may be to repress the expression of genes that are not normally expressed in the eye, but if misexpressed would result in a mutant phenotype. An example of such a gene is the pair-rule gene hairy. It has been shown recently by somatic mosaic 
analysis that hairy is not required for the development of the compound eye (Brown et al. 1991b). However, ectopic expression of hairy causes a wide range of abnormalities in the compound eye (Brown et al. 1991b). Because in vitro experiments demonstrate that $\mathrm{p} 69$ and not $\mathrm{p} 88$ binds the hairy promoter efficiently, the observation that the $t t k^{1}$ mutation had no effect on hairy expression in larval eye-imaginal discs was not surprising. Analysis of hairy expression in $t k^{1 e 11}$ mosaic patches in eye discs would be required to determine whether $\mathrm{p} 88$ regulates hairy expression during eye development. Future experiments directed at examining the consequences of overexpressing en in eye-imaginal discs, salivary glands, and fat bodies might provide evidence in support of a physiologically relevant role for $\mathrm{p} 88$ in repressing en expression.

\section{Materials and methods}

\section{Genetics}

The $t t k$ mutant $\left(t t k^{1}\right)$ was identified among 6000 homozygous viable P-element insertion lines generated in Dr. Allan Spradling's laboratory (Department of Embryology, Carnegie Institution of Washington, Baltimore, MD). These fly stocks typically contained one, and occasionally two, autosomal copies of a modified mutator P-element consisting of a rosy ${ }^{+}\left(\mathrm{ry}^{+}\right)$gene, a copy of the pHSS7 plasmid, and a $\beta$-galactosidase reporter gene.

The $t t k^{1}$ allele was identified by viewing the image of the deep pseudopupil as described previously (Franceschini and Kirschfeld 1971). Briefly, $w^{+}$flies were anesthetized with ether, transferred to a clear plexiglass platform, and examined with a Zeiss stereomicroscope by directing intense white light from below the flies using a biforcated fiber optic cable. The optical neutralization technique (Franceschini and Kirschfeld 1971) was used as a secondary screen by introducing a drop of immersion oil into a ring of dried nail polish on a microscope slide and immersing dissected fly heads in the immersion oil. A coverslip was placed on top of the sample, and the image of the rhabdomeres was examined on a Nikon Microphot-FXA microscope using very bright anadromic illumination with the condensor diaphragm iris closed to the minimum opening.

To demonstrate that the P-element induced the $t t k^{1}$ mutation, the P-element was mobilized by crossing $t t k^{1}$ flies with a stock referred to as jumpstarter, $c n ; \Delta 2-3, r y^{+}, S b / T M 6$, which provides the P-element transposase required in trans for transposition. Among $19 \mathrm{ry}^{-}$lines that were established, 14 reverted to wild type, 4 were recessive lethals, and 1 homozygous viable line exhibited a mutant eye phenotype.

To confirm that $t t k^{1}$ mapped to $100 \mathrm{D}$ near the right teleomere of the third chromosome and to ascertain whether $t \mathrm{tk}^{1}$ was a null allele, we crossed $t t k^{1}$ to a stock, Dfawd(3R $)^{K R B}$, containing a small deficiency at 100D (Biggs et al. 1990).

Somatic mosaic analysis was performed by generating $\mathrm{X}$-rayinduced mitotic recombination between $t t k^{+}$and $t t k^{-}$chromosomes. To differentiate $t t k^{+}$and $t t k^{-}$clones, the white gene was used as a cell autonomous marker. Heterozygous, $w^{-}$; $t t \mathrm{k}^{1 e 11} / \mathrm{w} ; \mathrm{P}\left[\mathrm{w}^{+}\right], t t \mathrm{k}^{+}$, late first-instar larvae at $48 \pm 6 \mathrm{hr}$ of development were exposed to 250 rads for $5 \mathrm{~min}$ to induce mitotic recombination. The $w^{1118} ; \mathrm{P}\left[w^{+}\right] \mathrm{D} 3$ stock has a P-element containing a $w^{+}$gene proximal to the $t t k$ gene at position $90 \mathrm{~F}$ on the third chromosome. Mosaic eyes were examined by scanning and transmission electron microscopy (TEM) as described below.
The nin $a E^{I 17}, t t k^{1}$ double mutant was created by meiotic recombination.

\section{Electron microscopy}

The $t t k$ eye phenotype was examined at the ultrastructural level by TEM. Hemisected fly heads were fixed in paraformaldehyde and glutaraldehyde, postfixed in osmium tetroxide, dehydrated in an ethanol series, infiltrated in a mixture of propylene oxide and Spurr's medium, and imbedded in Spurr's medium as described (Porter et al. 1992). Thin sections were examined by TEM. Scanning electron microscopy (SEM) was performed by placing dissected adult fly heads on aluminum pin mounts, using double-sided transparent tape, and viewed on an Amray SEM model 1810. The fly heads were not sputter-coated with platinum or treated in any way before SEM analyses.

\section{Isolation of ttk genomic DNA and determination} of P-element insertion site

The DNA sequences flanking the P-element insertion site were recovered by the plasmid rescue technique. In this technique, the pHSS7 plasmid inserted into the P-element is used to facilitate cloning the genomic DNA flanking the $5^{\prime}$ end of the P-element. To perform the plasmid rescue technique, $t t k$ genomic DNA was digested with $\mathrm{XbaI}$ and SpeI, a portion of the DNA, roughly equal to two fly equivalents of DNA, was then ligated under conditions to favor intramolecular ligation and transformed into competent Escherichia coli prepared by the procedure of Hanahan (1983). A 4.5-kb segment of genomic DNA, extending to a SpeI site, was recovered in the rescued plasmid pRPttk and used to screen a wild-type bacteriophage $\lambda$ genomic library. Among the genomic clones isolated was $\lambda t t k-1$, which contained a $16.0-\mathrm{kb}$ insert. The P-element insertion site in $\lambda t t k-1$ was determined by performing double-stranded DNA sequence analysis using pRPttk and a primer, GTATACTTCGGTAAGCTTCGGCTTT, complementary to the $5^{\prime}$ end of the P-element (nucleotides 56-32). The extent of genomic and P-element DNA deleted in $t k^{1 e 11}$ was determined by Southern blot analyses of genomic DNA prepared from each fly strain.

\section{RNA blots and identification of transcribed region}

To identify the transcribed region, $\lambda t t k-1$ was digested with various restriction enzymes, transferred to GeneScreen Plus (New England Nuclear), and probed with ${ }^{32} \mathrm{P}$-labeled cDNA prepared from adult RNA. Restriction fragments, extending from the Sall site at coordinate 3.1 to the BamHI site at coordinate 11.5 , hybridized most strongly with the cDNA (Fig. 1). To perform RNA blots, total RNA was prepared as described, transferred to GeneScreen Plus, and probed with the ${ }^{32} \mathrm{P}$-labeled DNA fragments indicated in the legends to Figures 2 and 3.

\section{Isolation and sequencing of cDNAs}

An eye disc cDNA library was screened with the ${ }^{32} \mathrm{P}$-labeled 4.5-kb genomic region contained in the rescued plasmid pRPttk. The filters were hybridized and washed as described (Montell et al. 1987). Among the cDNA isolated was pcttk-3.7 (3704 nucleotides) and pcttk-4.5 (4524 nucleotides), which corresponded to the 4.2- and 5.0-kb mRNAs. pcttk-3.7, but not pcttk-4.5, contained a poly $(\mathrm{A})$ tail. To map the approximate genomic region encoding each cDNA, a Southern blot containing $\lambda t t k-1$ DNA was probed with ${ }^{32} \mathrm{P}$-labeled pcttk-3.7 and pcttk-4.5.

The cDNAs were sequenced by the dideoxy chain termination method using Sequenase. The template DNAs used for the 
DNA sequencing were generated by the random shearing of pcttk-3.7 and pcttk-4.5 by sonication and the subcloning of fragments into the SmaI site of $\mathrm{M} 13 \mathrm{mpl} 10$ as described previously (Montell et al. 1987). Recombinant M13 clones containing cDNA inserts were identified by plaque hybridizations using ${ }^{32} \mathrm{P}$-labeled purified cttk-3.7 and cttk-4.5 fragments.

\section{Immunostaining of wild-type and ttk tissues}

Wild-type and $t t k^{1}$ larval tissues were dissected in $0.1 \mathrm{~m}$ sodium phosphate $(\mathrm{pH} 7.2)$ and fixed for $45 \mathrm{~min}$ in $2 \%$ paraformaldehyde, $0.01 \%$ sodium iodate, $0.075 \mathrm{M}$ lysine, and $0.037 \mathrm{M}$ sodium phosphate $(\mathrm{pH} \mathrm{7.2)}$ as described previously (Tomlinson and Ready 1987) and stained with mouse monoclonal antisera to $f t z$ and $e n$. A heterogeneous overnight collection $\left(18^{\circ} \mathrm{C}\right)$ of wildtype and $t t k^{1 e 11} /+$ embryos were fixed and stained with $f t z$, eve, and en as described previously (Patel et al. 1989). An overnight collection of $t t k^{1}$ embyos were also stained with $f t z$ and en as described (Patel et al. 1989).

\section{Acknowledgments}

We thank T. Oyebade and J. Li for technical assistance with the microscopy, Dr. A.S. Spradling and members of his laboratory for providing the P-element insertion lines, and the following members of the Montell laboratory for screening the P-element insertion lines: Dr. H. Okano, Dr. J. Blendy, A. Thomas, and T. Oyebade. We thank Dr. A. Shearn for providing the deficiency stock Df(3R)awd $d^{K R B}$ and for use of his X-ray machine, Dr. K. Moses for the stock $w^{1118}$; $\mathrm{P}\left[w^{+}\right] \mathrm{D} 3$ used in the mosaic analysis, and Dr. T. Schroer for use of the video-enhanced microscopy. We are especially grateful to Drs. N.H. Patel and D.J. Montell for assistance in examining the $t k^{1 e 11}$ and $t t k^{1}$ embryos and Dr. D.F. Ready for assistance in examining the eye-imaginal discs and for helpful discussions. We also thank Dr. N.H. Patel for providing the eve and en antisera, Dr. J.L. Manley for providing the $t t k$ antisera, Dr. H. Krause for the $f t z$ antisera, Drs. J.L. Manley, J.L. Brown, and C. Wu for communicating results before publication, and Drs. D.J. Montell and P. Beachy for helpful comments on the manuscript. This work was supported by a grant from the American Cancer Society (NP-798) to C.M. C.M. also acknowledges support from a National Science Foundation Presidential Young Investigator Award and an American Cancer Society Junior Faculty Research Award.

The publication costs of this article were defrayed in part by payment of page charges. This article must therefore be hereby marked "advertisement" in accordance with 18 USC section 1734 solely to indicate this fact.

\section{Note added in proof}

The sequence data described in this paper have been submitted to the EMBL/GenBank data libraries under accession numbers X71626 and X71627.

\section{References}

Ashburner, M. 1989. Clearing and mounting embryos. In Drosophila: A laboratory manual. pp. 153-154. Cold Spring Laboratory Press, Cold Spring Harbor, New York.

Baker, N.E. and G.M. Rubin. 1989. Effect on eye development of dominant mutations in the Drosophila homologue of the EGF receptor. Nature 340: 150-153.

Baker, N.E., M. Mlodzik, and G.M. Rubin. 1990. Spacing differ- entiation in the developing Drosophila eye: A fibrinogenrelated lateral inhibitor encoded by scabrous. Science 250: 1370-1377.

Basler, K., D. Yeh, and E. Hafen. 1990. Reprogramming cell fate in the developing Drosophila retina: Transformation of R7 cells by ectopic expression of rough. Genes \& Dev. 4: 728739.

Basler, K., B. Christen, and E. Hafen. 1991. Ligand-independent activation of the sevenless receptor tyrosine kinase changes the fate of cells in the developing Drosophila eye. Cell 64: 1069-1081.

Bieber, A.J., P.M. Snow, M. Hortsch, N.H. Patel, J.R. Jacobs, Z.R. Traquina, J. Schilling, and C.S. Goodman. 1989. Drosophila neuroglian: A member of the immunoglobulin superfamily with extensive homology to the vertebrate neural adhesion molecule L1. Cell 59: 447-460.

Biggs, J., E. Hersperger, P.S. Steeg, L.A. Liotta, and A. Shearn. 1990. A Drosophila gene that is homologous to a mammalian gene associated with tumor metastasis codes for a nucleoside diphosphate kinase. Cell 63: 933-940.

Bonfini, L., C.A. Karlovich, C. Dasgupta, and U. Banerjee. 1992. The Son of Sevenless gene product: A putative activator of Ras. Science 255: 603-606.

Brown, J.L., S. Sonoda, H. Ueda, M.P. Scott, and C. Wu. 199la. Repression of the Drosophila fushi tarazu (ftz) segmentation gene. EMBO I. 10: 665-674.

Brown, N.L., C.A. Sattler, D.R. Markey, and S.B. Carroll. 1991 b. hairy gene function in the Drosophila eye: Normal expression is dispensible but ectopic expression alters cell fates. Development 113: 1245-1256.

Brown, J.L. and C. Wu. 1993. Repression of Drosophila pair-rule segmentation genes by ectopic expression of tramtrack. Development 117: 45-58.

Buckles, G.R., Z.D.J. Smith, and F.N. Katz. 1992. mip causes hyperinnervation of a retinotopic map in Drosophila by excessive recruitment of R7 photoreceptor cells. Neuron 8: 1015-1019.

Cagan, R.L. and D.F. Ready. 1989. Notch is required for successive cell divisions in the developing Drosophila retina. Genes \& Dev. 3: 1099-1112.

Carthew, R.W. and G.M. Rubin. 1990. seven in absentia, a gene required for specification of $R 7$ cell fate in the Drosophila eye. Cell 63: 561-577.

Dickson, B., F. Sprenger, D. Morrison, and E. Hafen. 1992. Raf functions downstream of Rasl in the Sevenless signal transduction pathway. Nature 360: 600-603.

Fortini, M.E., M.A. Simon, and G.M. Rubin. 1992. Signalling by the sevenless protein tyrosine kinase is mimicked by Ras 1 activation. Nature 355: 559-561.

Franceschini, N. and K. Kirschfeld. 1971. Les phénomènes de pseudopupille dans l'oeil composé de Drosophila. Kybertik 9: 152-182.

Freeman, M., C. Klämbt, C.S. Goodman, and G.M. Rubin. 1992. The argos gene encodes a diffusible factor that regulates cell fate decisions in the Drosophila eye. Cell 69: 963-975.

Gaul, U., G. Mardon, and G.M. Rubin. 1992. A putative Ras GTPase activating protein acts as a negative regulator of signaling by the sevenless receptor tyrosine kinase. Cell 68: 1007-1019.

Greenwald, I. and G.M. Rubin. 1992. Making a difference: The role of cell-cell interactions in establishing separate identities for equivalent cells. Cell 68: 271-281.

Hafen, E., K. Basler, J.-E. Edstoem, and G.M. Rubin. 1987. Sevenless, a cell-specific homeotic gene of Drosophila, encodes a putative transmembrane receptor with a tyrosine kinase domain. Science 236: 55-63. 
Hanahan, D. 1983. Studies on tranformation of Escherichia coli with plasmids. $J$. Mol. Biol. 166: 557-580.

Harrison, S.D. and A.A. Travers. 1990. The tramtrack gene encodes a Drosophila finger protein that interacts with the $\mathrm{ftz}$ transcriptional regulatory region and shows a novel embryonic expression pattern. EMBO I. 9: 207-216.

Karpen, G.H. and A.S. Spradling. 1992. Analysis of subtelomeric heterochromatin in Drosophila minichromosome Dpl187 by single $\mathrm{P}$ element insertion mutagenesis. Genetics 132: 737-752.

Kimmel, B.E., U. Heberlein, and G.M. Rubin. 1990. The homeo domain protein rough is expressed in a subset of cells in the developing Drosophila eye where it can specify photoreceptor cell subtype. Genes \& Dev. 4: 712-727.

Kramer, H., R.L. Cagan, and S.L. Zipursky. 1991. Interaction of bride of sevenless membrane-bound ligand and the sevenless tyrosine-kinase receptor. Nature 352: 207-212.

Kretzschmar, D., A. Brunner, V. Wiersdorff, G.O. Pflugfelder, M. Heisenberg, and S. Schneuwly. 1992. giant lens, a gene involved in cell determination and axon guidance in the visual system of Drosophila melanogaster. EMBO J. 11: 25312539.

Lai, Z.-C. and G.M. Rubin. 1992. Negative control of photoreceptor development in Drosophila by the product of the yan gene, an ETS domain protein. Cell 70: 609-620.

Mlodzik, M., Y. Hiromi, U. Weber, C.S. Goodman, and G.M. Rubin. 1990. The Drosophila seven-up gene, a member of the steroid receptor gene superfamily, controls photoreceptor cell fates. Cell 60: 211-224.

Montell, C., K. Jones, C. Zuker, and G. Rubin. 1987. A second opsin gene expressed in the ultraviolet-sensitive R7 photoreceptor cells of Drosophila melanogaster. I. Neurosci. 7: 1558-1566.

Moses, K. 1991. The role of transcription factors in the developing Drosophila eye. Trends Genet. 7: 250-255.

Moses, K. and G.M. Rubin. 1991. glass encodes a site-specific DNA-binding protein that is regulated in response to positional signals in the developing Drosophila eye. Genes \& Dev. 5: 583-593.

Moses, K., M.C. Ellis, and G.M. Rubin. 1989. The glass gene encodes a zinc-finger protein required by Drosophila photoreceptor cells. Nature 340: 531-536.

Moses, K. 1991. The role of transcription factors in the developing Drosophila eye. Trends Genet. 7: 250-255.

Okano, H., S. Hayashi, T. Tanimura, K. Sawamoto, S. Yoshikawa, J. Watanabe, M. Iwasaki, S. Hirose, K. Mikoshiba, and C. Montell. 1992. Regulation of Drosophila neural development by a putative secreted protein. Differentation 52: 1-11.

O'Tousa, J.E., D.S. Leonard, and W.L. Pak. 1989. Morphological defects in or $^{I K 84}$ photoreceptors caused by mutation in R1R6 opsin gene of Drosophila. J. Neurogenet. 6: 41-52.

Patel, N.H., E. Martin-Blanco, K.G. Coleman, S.J. Poole, M.C. Ellis, T.B. Kornberg, and C.S. Goodman. 1989. Expression of engrailed proteins in arthropods, annelids, and chordates. Cell 58: 955-968.

Porter, J.A., J.L. Hicks, D.S. Williams, and C. Montell. 1992. Differential localizations of and requirements for the two Drosophila ninaC kinase/myosins in Drosophila photoreceptor cells. I. Cell Biol. 116: 683-693.

Read, D. and J.L. Manley. 1992. Alternatively spliced transcripts of the Drosophila tramtrack gene encode zinc finger proteins with distinct DNA binding specificities. EMBO J. 11: 1035-1044.

Read, D., M. Levine, and J.L. Manley. 1992. Ectopic expression of the Drosophila tramtrack gene results in multiple embry- onic defects, including repression of even-skipped and fushi tarazu. Mech. Dev. 38: 183-196.

Reinke, R. and S. L. Zipursky. 1988. Cell-cell interaction in the Drosophila retina: The bride of sevenless gene is required in photoreceptor cell R8 for R7 cell development. Cell 55: 321330.

Rogge, R.D., C.A. Karlovich, and U. Banerjee. 1991. Genetic dissection of a neurodevelopmental pathway: Son of sevenless functions downstream of the sevenless and EGF receptor tyrosine kinases. Cell 64: 39-48.

Rogge, R., R. Cagan, A. Majumdar, T. Dulaney, and U. Baneriee. 1992. Neuronal development in the Drosophila retina: The sextra gene defines an inhibitory component in the developmental pathway of R7 photoreceptor cells. Proc. Natl. Acad. Sci. 89: 5271-5275.

Simon, M.A., D.D.L. Bowtell, and G.M. Rubin. 1989. Structure and activity of the sevenless protein: A protein tyrosine kinase receptor required for photoreceptor development in Drosophila. Proc. Natl. Acad. Sci. 86: 8333-8337.

Simon, M.A., D.D.L. Bowtell, G.S. Dodson, T.R. Laverty, and G.M. Rubin. 1991. Ras1 and a putative guanine nucleotide exhange factor perform crucial steps in signalling by the sevenless protein tyrosine kinase. Cell 67: 701-716.

Tomlinson, A. and D.F. Ready. 1987. Neuronal differentiation in the Drosophila ommatidium. Dev. Biol. 120: 366-376.

Tomlinson, A., B.E. Kimmel, and G.M. Rubin. 1988. rough, a Drosophila homeobox gene required in photoreceptor R2 and $\mathrm{R} 5$ for inductive interactions in the developing eye. Cell 55: 771-784.

Van Vactor, D.L. Jr., R.L. Cagan, H.L. Kramer, and S.L. Zipursky. 1991. Induction in the developing compound eye of Drosophila: Multiple mechanisms restrict R7 induction to a single retinal precursor cell. Cell 67: 1145-1155. 


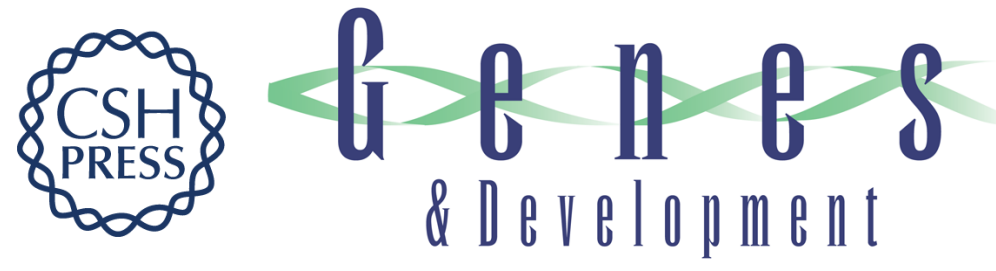

\section{tramtrack is a transcriptional repressor required for cell fate determination in the Drosophila eye.}

W C Xiong and C Montell

Genes Dev. 1993, 7:

Access the most recent version at doi:10.1101/gad.7.6.1085

References This article cites 47 articles, 14 of which can be accessed free at:

http://genesdev.cshlp.org/content/7/6/1085.full.html\#ref-list-1

License

Email Alerting

Service

Receive free email alerts when new articles cite this article - sign up in the box at the top right corner of the article or click here.

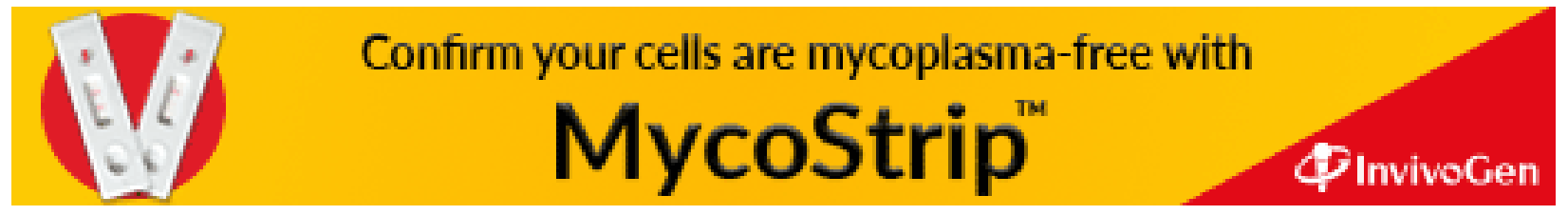

